\title{
The Unresolved Case of Sacral Chordoma: From Misdiagnosis to Challenging Surgery and Medical Therapy Resistance
}

\author{
Fabio Garofalo ${ }^{1,2}$, Dimitrios Christoforidis ${ }^{2,3}$, Pietro G. di Summa ${ }^{4}$, Béatrice Gay ${ }^{5}$, Stéphane Cherix ${ }^{6}$, \\ Wassim Raffoul ${ }^{4}$, Nicolas Demartines ${ }^{2}$, Maurice Matter ${ }^{2}$ \\ ${ }^{1}$ Department of Surgery, Intercantonal Hospital Broye, Payerne; ${ }^{2}$ Department of Visceral Surgery, University Hospital of Lausanne (CHUV), \\ Lausanne; ${ }^{3}$ Department of Surgery, Hospital Civico, Lugano; Departments of ${ }^{4}$ Plastic and Reconstructive Surgery, ${ }^{5}$ Oncology, and \\ ${ }^{6}$ Orthopedics, University Hospital of Lausanne (CHUV), Lausanne; Switzerland
}

Purpose: A sacral chordoma is a rare, slow-growing, primary bone tumor, arising from embryonic notochordal remnants. Radical surgery is the only hope for cure. The aim of our present study is to analyse our experience with the challenging treatment of this rare tumor, to review current treatment modalities and to assess the outcome based on R status.

Methods: Eight patients were treated in our institution between 2001 and 2011. All patients were discussed by a multidisciplinary tumor board, and an en bloc surgical resection by posterior perineal access only or by combined anterior/posterior accesses was planned based on tumor extension.

Results: Seven patients underwent radical surgery, and one was treated by using local cryotherapy alone due to low performance status. Three misdiagnosed patients had primary surgery at another hospital with R1 margins. Reresection margins in our institution were R1 in two and R0 in one, and all three recurred. Four patients were primarily operated on at our institution and had en bloc surgery with R0 resection margins. One had local recurrence after 18 months. The overall morbidity rate was $86 \%$ (6/7 patients) and was mostly related to the perineal wound. Overall, 3 out of 7 resected patients were disease-free at a median follow-up of 2.9 years (range, 1.6-8.0 years).

Conclusion: Our experience confirms the importance of early correct diagnosis and of an R0 resection for a sacral chordoma invading pelvic structures. It is a rare disease that requires a challenging multidisciplinary treatment, which should ideally be performed in a tertiary referral center.

Keywords: Sacrum; Chordoma; perineum

\section{INTRODUCTION}

A chordoma is a rare, slow-growing, primary bone tumor arising

Received: July 22, 2013 - Accepted: October 18, 2013

Correspondence to: Nicolas Demartines, M.D., FACS, FRCS

Department of Visceral Surgery, University Hospital of Lausanne (CHUV),

Rue du Bugnon 46, Lausanne 1011, Switzerland

Tel: +41-213142400, Fax: None

E-mail: demartines@chuv.ch

(c) 2014 The Korean Society of Coloproctology

This is an open-access article distributed under the terms of the Creative Commons Attribution NonCommercial License (http://creativecommons.org/licenses/by-nc/3.0) which permits unrestricted non-

commercial use, distribution, and reproduction in any medium, provided the original work is properly cited. from embryonic notochordal remnants. Chordomas constitute less than $5 \%$ of all primary bone neoplasms, tand heir incidence rate is $0.1 / 100,000$. The most common localization is the sacrococcygeal area (40\%-50\%) and the base of the skull (35\%-40\%), followed by the vertebral bodies (15\%-20\%) [1,2]. Sacrococcygeal chordomas usually require extensive composite resections including the sacrum, the anorectum and the pelvi-perineal muscle.

Local recurrence (LR) after surgical treatment is common $(43 \%-85 \%)$ even for an R0 resection [3, 4]. Distant disease is less frequent $(20 \%-40 \%)$, but metastases to the bone, lung, liver, lymph-nodes and skin have been described [3-7]. The 10-year overall survival (OS) rate ranges from $30 \%$ to $65 \%$ [5, 7-12]. Radical surgery is the only hope for cure as no chemotherapy has been 
demonstrated to be effective against a chordoma, and radiotherapy is only marginally effective $[5,7,9,13-15]$. The quality of the surgical margins achieved at primary surgery is the most important factor for recovery, but is often limited by inadequate diagnosis prior to surgery. The aim of this study is to present our experience with the challenging treatment of this rare, often misdiagnosed tumor. This work reviews current treatment modalities and assesses outcomes based on R Status.

\section{METHODS}

The University Hospital of Lausanne is the tertiary referral center for a population of about 1 million inhabitants in South-Eastern Switzerland. Through a combination of diagnostic and surgical procedure codes, we identified all patients treated for sacral tumours during the period from 2001 to 2011 in our academic institution. Charts were examined to identify patients with a diagnosis of sacral chordoma. We included patients who underwent primary surgery in our institution, surgery for LR after primary surgery performed elsewhere and patients who underwent palliative treatment. All patients had extensive pre-operative work-ups with computed tomography (CT) and magnetic resonance imaging (MRI). The treatment strategy was discussed by a multidisciplinary tumor board for sarcomas based on our internal policy. According to tumor's extension and resectability, the surgical approach was discussed, and en bloc resection was planned either by a posterior perineal approach only or by a combined anteroposterior approach.
For the combined approach, the patient was first operated on in the supine position. Pelvic dissection was pursued down to the predefined sacrectomy level where a piece of gauze was left, an omental flap was prepared and positioned in the pelvis, the sigmoid was transfected, an end-colostomy was fashioned, and the abdomen was closed. The patient was then turned and positioned prone with legs abducted. A perineal dissection with an en bloc sacrectomy was then completed. The defect was closed either with a combination of omentoplasty, absorbable mesh and direct wound closure or with temporary vacuum-assisted closure and secondary reconstruction with myocutaneous flaps for larger defects. The resection status was considered R0 if surgical margins were $\geq 1 \mathrm{~mm}$ [16]. The special feature of our patients was the involvement of pelvic visceral elements in all of them. Our institution has a dedicated surgical team specialized in sarcoma treatment; the team includes oncologic surgeons and orthopedists working together with plastic and reconstructive surgeons.

\section{RESULTS}

\section{Treatment and outcome}

Eight patients were treated in our institution between 2001 and 2011 for sacral chordoma. One patient unfit for surgery was treated by using local cryoablation with tumor palliative intent. The seven remaining patients underwent a curative surgical resection of the tumor (Table 1). Three (patients \#1, \#2, and \#4) had had primary surgery in another hospital and were referred to our hospital after LR. The diagnosis was not suspected prior to the

Table 1. Details of the patients and their outcomes

\begin{tabular}{|c|c|c|c|c|c|c|c|c|c|}
\hline No & $\begin{array}{l}\text { Age/ } \\
\text { gender }\end{array}$ & $\begin{array}{l}\text { Year } \\
\text { of Dx }\end{array}$ & $\begin{array}{l}\text { Primary } \\
\text { surgery }\end{array}$ & $\begin{array}{c}\text { Bone } \\
\text { resection level }\end{array}$ & $\begin{array}{c}\text { Muscle } \\
\text { resection level }\end{array}$ & $\begin{array}{l}\text { Margins } \\
\text { /MDT }\end{array}$ & $\begin{array}{l}\text { Local } \\
\text { recurrence }\end{array}$ & $\begin{array}{l}\text { Reoperation/ } \\
\text { margins/MDT }\end{array}$ & $\begin{array}{l}\text { Follow-up/ } \\
\text { status }\end{array}$ \\
\hline 1 & $43 / M$ & 1998 & PA/elsewhere & S4 & $\begin{array}{l}\text { GM bil. } \\
\text { Piri. bil. }\end{array}$ & R1 & Yes 24 mo & PA/R1; CA/Rx & $14 \mathrm{yr} / \mathrm{AWD}$ \\
\hline 2 & $58 / F$ & 2001 & PA/elsewhere & S4 & GM bil. & $\mathrm{R} 1$ & Yes 24 mo & PA/R1 & $11 \mathrm{yr} / \mathrm{DOD}$ \\
\hline 3 & $62 / \mathrm{M}$ & 2004 & PA & S3 & $\begin{array}{l}\text { GM bil. } \\
\text { Piri. bil. }\end{array}$ & $\mathrm{R} 0 / 0.2 \mathrm{~cm}$ & No & No & 8 yr/AFD \\
\hline 4 & $40 / \mathrm{M}$ & 2008 & PA/elsewhere & S5-coccyx & GM bil. & R1 & Yes 11 mo & CA/RO: $0.05 \mathrm{~cm}$ & $4.7 \mathrm{yr} / \mathrm{AWD}$ \\
\hline 5 & $60 / F$ & 2010 & CA & $\mathrm{S} 1-\mathrm{S} 2$ & $\begin{array}{l}\text { Levator ani } \\
\text { Piri. bil. } \\
\text { GM bil. }\end{array}$ & $\mathrm{R} 0 / 0.5 \mathrm{~cm}$ & No & No & $2.9 \mathrm{yr} / \mathrm{AFD}$ \\
\hline 6 & $32 / F$ & 2011 & $\mathrm{CA}$ & S3 & $\begin{array}{l}\text { Levator ani } \\
\text { Piri bil. } \\
\text { GM bil. } \\
\text { Obturator intemus }\end{array}$ & $\mathrm{R} 0 / 0.5 \mathrm{~cm}$ & No & No & $1.6 \mathrm{yr} / \mathrm{AFD}$ \\
\hline 7 & $34 / M$ & 2011 & $\mathrm{CA}$ & S3 & $\begin{array}{l}\text { Levator ani } \\
\text { Piri. bil. } \\
\text { GM bil. }\end{array}$ & $\mathrm{R} 0 / 1 \mathrm{~cm}$ & Yes $18 \mathrm{mo}$ & No & $1.8 \mathrm{yr} / \mathrm{AWD}$ \\
\hline
\end{tabular}


primary resection. Four patients ( $\# 3$, \#5, \#6, and \#7) who had undergone a preoperative diagnostic core-needle biopsy had primary surgery in our institution.

The patients operated elsewhere (\#1, \#2, and \#4) all had R1 margins. They developed LR (or disease progression) at 24, 24, and 11 months, respectively, and were operated on secondarily at our institution. Patient \#4 had a reresection through a combined anteroposterior approach with negative margins (R0). Of note is the fact that he presented a positive, clinically-enlarged external iliac lymph node on frozen section, so a radical ilio-obturator lymphnode dissection was added. No further positive lymph-nodes were found. He had a local rerecurrence 2 years later. Patients \#1 and $\# 2$ were reoperated on by using a posterior approach only, and both had still positive margins (R1) and further loco-regional rerecurrence. Patient \#1 underwent a third operation, a combined anteroposterior approach, with palliative intent. He received adjuvant radiotherapy and imatinib mesylate therapy. He is currently alive with residual disease 14 years after the initial diagnosis. Recurrences in patients \#2 and \#4 were treated with palliative radiation therapy (RT), local radiofrequency ablation and imatinib mesylate therapy. Patient \#2 died of disease 11 years after the primary diagnosis. Patient \#4 is still alive with residual disease 4.7 years after the initial diagnosis.

The four patients who were resected primarily in our hospital and who had a known preoperative diagnosis underwent en bloc surgery with R0 resection margins (Fig. 1). This radical surgery was performed in collaboration with orthopedic and spine surgeons. One patient (\#3) underwent a posterior approach only with primary closure of the pelvic floor. The operative time was 5 hours. The other three patients underwent a combined antero-
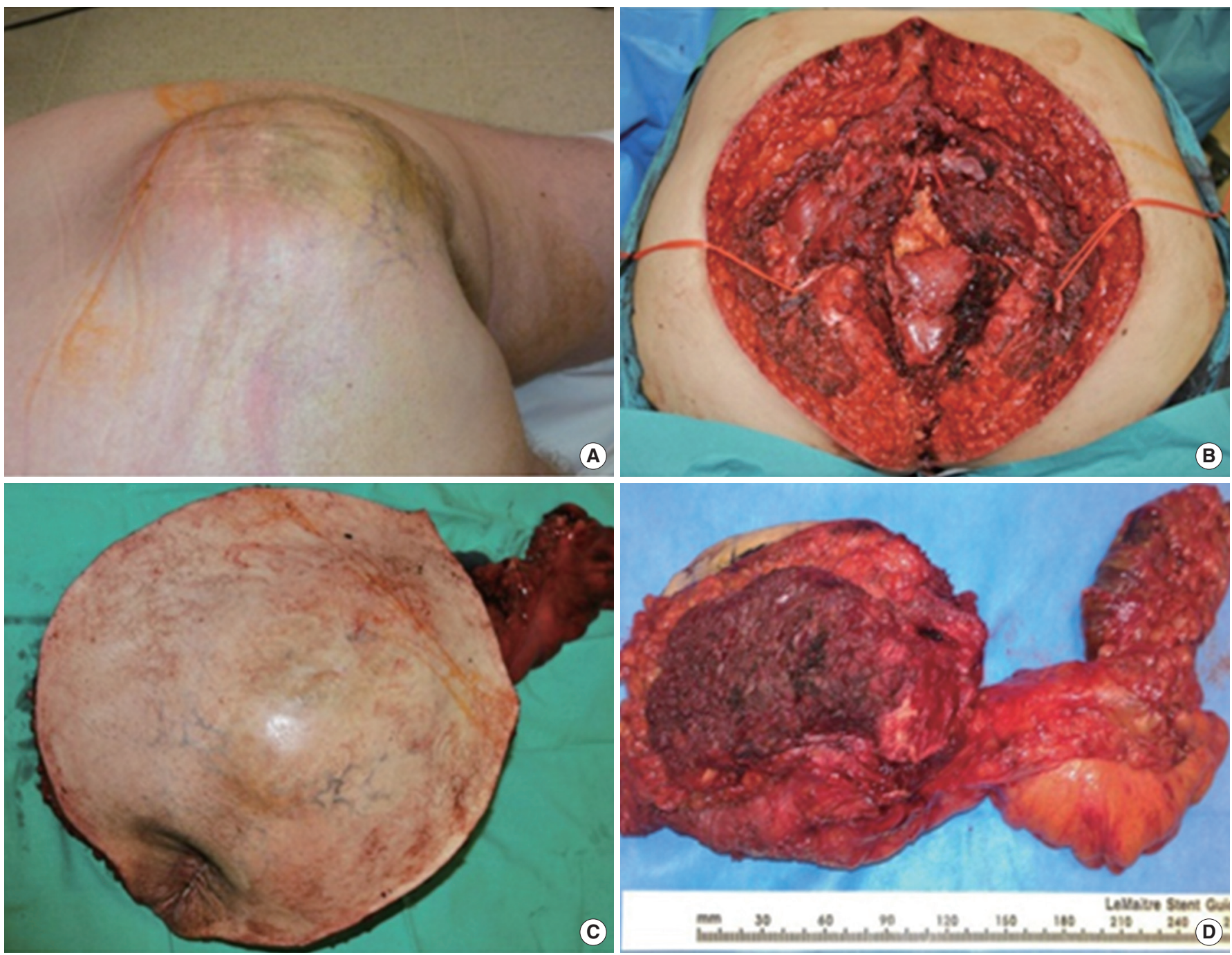

Fig. 1. (A) Clinical presentation of the sacral chordoma in patient \#7. (B) Pelvic floor resection of asacral chordoma treated by using a combined approach. (C, D) En bloc resection with skin and smooth perineal tissue, the sacrum and the rectum. 
Table 2. Reconstruction surgery and complications

\begin{tabular}{|c|c|c|c|c|c|c|c|c|}
\hline No & $\begin{array}{c}\text { Age/ } \\
\text { gender }\end{array}$ & $\begin{array}{c}\text { Last } \\
\text { surgery }\end{array}$ & $\begin{array}{l}\text { Resection } \\
\text { level }\end{array}$ & $\begin{array}{l}\text { Immediate } \\
\text { procedure }\end{array}$ & $\begin{array}{c}\text { Early } \\
\text { reconstruction }\end{array}$ & $\begin{array}{c}\text { Wound } \\
\text { complication }\end{array}$ & $\begin{array}{c}\text { Delayed } \\
\text { reconstruction }\end{array}$ & $\begin{array}{c}\text { Time to } \\
\text { complete healing }\end{array}$ \\
\hline 1 & 43/M & CA & S3 & GF & - & Dehiscence & No & $2 \mathrm{mo}$ \\
\hline 2 & 58/F & PA & $\mathrm{S} 1-\mathrm{S} 2$ & $\mathrm{DC}$ & No & Dehiscence & No & $3 \mathrm{mo}$ \\
\hline 3 & $62 / \mathrm{M}$ & PA & S3 & $\mathrm{DC}$ & No & No & No & $3 w k$ \\
\hline 4 & $40 / \mathrm{M}$ & CA & S3 & VAC & ALT & No & No & $1 \mathrm{mo}$ \\
\hline 5 & $60 / F$ & CA & $\mathrm{S} 1-\mathrm{S} 2$ & $\mathrm{DC}$ & No & Dehiscence & GF & $5 \mathrm{mo}$ \\
\hline 6 & $32 / F$ & CA & S3 & $\mathrm{DC}$ & No & Dehiscence & No & $5 \mathrm{mo}$ \\
\hline 7 & $34 / \mathrm{M}$ & CA & S3 & VAC & ALT & Necrosis & GF & $2 \mathrm{mo}$ \\
\hline
\end{tabular}

CA, combined approach; PA, posterior approach; VAC, vacuum assisted closure system; GF, gluteus maximus flap; ALT, Antero-lateral thigh flap; DC, direct closure.

posterior approach. Patient \#5 had undergone neo-adjuvant radiotherapy. Cumulative operative times (reconstructive surgery included) were $5,18.5$, and 15.5 hours for patients \#5, \#6, and \#7, respectively. Three of the patients operated on primarily in our institution, patients $\# 3$, \#5, and \#6, remain disease-free with follow-ups of 1.6, 2.9, and 8 years, respectively; patient \#7, presenting with an initial $12.5-\mathrm{cm} \times 13-\mathrm{cm}$ mass infiltrating the mesorectum, developed LR and bilateral lung metastasis 18 months after surgery (Fig. 1).

\section{Perineal wound closure and surgical morbidity}

According to the extent of surgery and the need for vascularized tissue to fill the space after resection, different options were taken to close the perineal wound (Table 2). Direct wound closure was possible in four of the seven patients (\#2, \#3, \#5, and \#6), but three of them (\#2, \#5, and \#6) developed wound dehiscence. In two cases, wounds healed by secondary intention. One patient (\#5) was treated by using vacuum-assisted closure (VAC, KCI Concepts, San Antonio, TX, USA) during two months, and definitive repair was achieved with bilateral rotational gluteal flaps.

When direct closure was not feasible, four out of the seven patients, reconstruction with large flaps was performed by plastic surgeons. In two patients (\#1 and \#5), reconstruction was carried out with bilateral or single gluteal fasciocutaneous rotational flaps (operative times of 3 and 1.5 hours, respectively) during the same operation in patient \#1 or after complete dehiscence of the primary closure in patient \#5. For the other two patients (\#4 and \#7), due to a large perineal defect, we decided to wait for the final histologic assessment of resection margins prior to definitive repair. The wound was temporarily closed with Vicryl mesh and VAC, and 15 and 21 days later, definitive reconstruction was achieved with a pediculated myocutaneous anterolateral thigh (ALT) flap including the vastus lateralis muscle to increase bulkiness and fill the dead space (operative times of 6.5 and 5 hours, respectively). In both cases, the fascia lata was included in the flap to reinforce the perineum. Three out of four patients who underwent reconstructive procedures presented postoperative complications. $\mathrm{Pa}$ tient \#1 presented with a caudal dehiscence one month after a flap procedure using a rotational fasciocutaneous flap based on inferior gluteal perforators. Healing was achieved after debridement and refixation of the flap. Patient \#5 developed a medial dehiscence between the two flaps, requiring debridement and direct closure one month after the reconstructive procedure. For patient \#7, the flap presented a venous congestion at postoperative day 1 due to excessive tension closure; a surgical re-exploration was required. The partial flap necrosis was debrided, and two further operations with mobilizations of the local gluteal fasciocutaneous flaps (three and four weeks postoperatively, respectively) were necessary to achieve definitive wound healing and closure.

The overall morbidity rate was $86 \%$ (6/7 patients) and was mainly related to the perineal wound. A pelvic lymphocele was detected in 4/7 patients and an abdominal wall abscess in 2/5 patients who underwent a combined approach. Bladder dysfunction was observed in 3/7 patients, and erectile dysfunction in one of the four men. Two of the seven patients complained of chronic perineal pain. For patients operated on in our institution, the median hospital stay was 30 days (range, 7-184 days).

\section{DISCUSSION}

Our small series of patients treated for a sacral chordoma invading the perineum and adjacent visceral structures emphasizes the complexity of this type of surgical treatment. Our results confirm that chances to obtain an $\mathrm{R} 0$ resection are higher for patients who have an accurate preoperative diagnosis and who undergo an aggressive multidisciplinary treatment rather than for patients who have been misdiagnosed and are in need of secondary surgery [3, $4,11,13$. The quality of surgical margins at initial surgery is the primary prognostic factor for $\operatorname{LR}[7,11,12,17-19]$, with the 10 year OS rates ranging between $30 \%$ and $65 \%$ depending on the surgical margins $[5,7,8-12]$. A review of the recent literature shows LR rates ranging between $0 \%$ and $60 \%$ for wide margins, between $31 \%$ and $71 \%$ for marginal margins, and between $67 \%$ and $100 \%$ for intralesional resection margins (Table 3).

Sacral chordomas often present with nonspecific signs and symptoms, which can delay diagnosis. Indeed, the majority of 


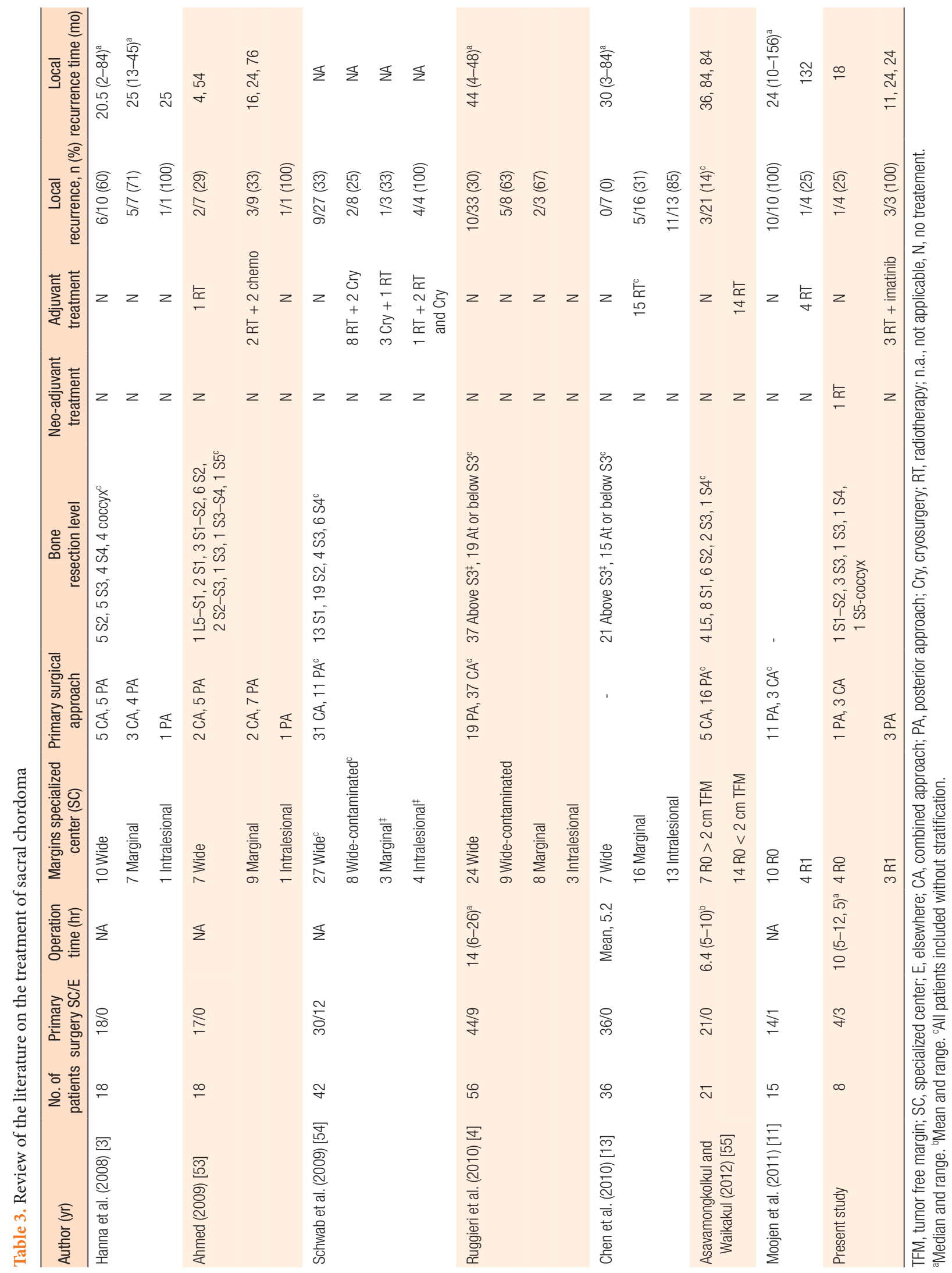


sacral chordomas reported in the literature are proximal lesions at or above S3 (Table 3). In the absence of a preoperative diagnosis and a well-prepared multidisciplinary team, the risk of violating tumor margins is very high. A differential diagnosis for sacral chordomas includes pilonidal sinus disease, deep abscesses, rectal sarcomas, and several retrorectal tumors (teratomas, extraperitoneal adenomucinosis, cystic lymphangiomas, neurogenic tumors and cysts, developmental tailgut cysts, sacral myelomeningocele, and rectal duplication) [20-22]. The typical clinical presentation for a sacral chordoma is a slow-growing palpable mass in the sacrum that is often painless, is without inflammatory or infectious signs, and is rarely associated with rectal dysfunction or urinary incontinence at the time of diagnosis. Unlike developmental cysts, chordomas almost never get infected or cause fistulization, but demonstrate bone destruction on radiological imaging, which is very uncommon with all other benign retrorectal lesions. Diagnosis is made by using CT and MRI, which are crucial to define the extent of the disease. On a CT scan, sacral chordomas show large lytic lesions centred in the midline and an associated softtissue mass. Calcifications are present in $30 \%-70 \%$ of the cases. On MRI, sacral chordomas, compared with skeletal muscle, have an isointense or slightly hypointense signal on T1-weighted images and are typically hyper-intense on T2-weighted images [23] (Fig. 2). Core-needle biopsy by an experienced radiologist is mandatory to obtain a definitive diagnosis and to adequately plan an extensive and debilitating surgery.
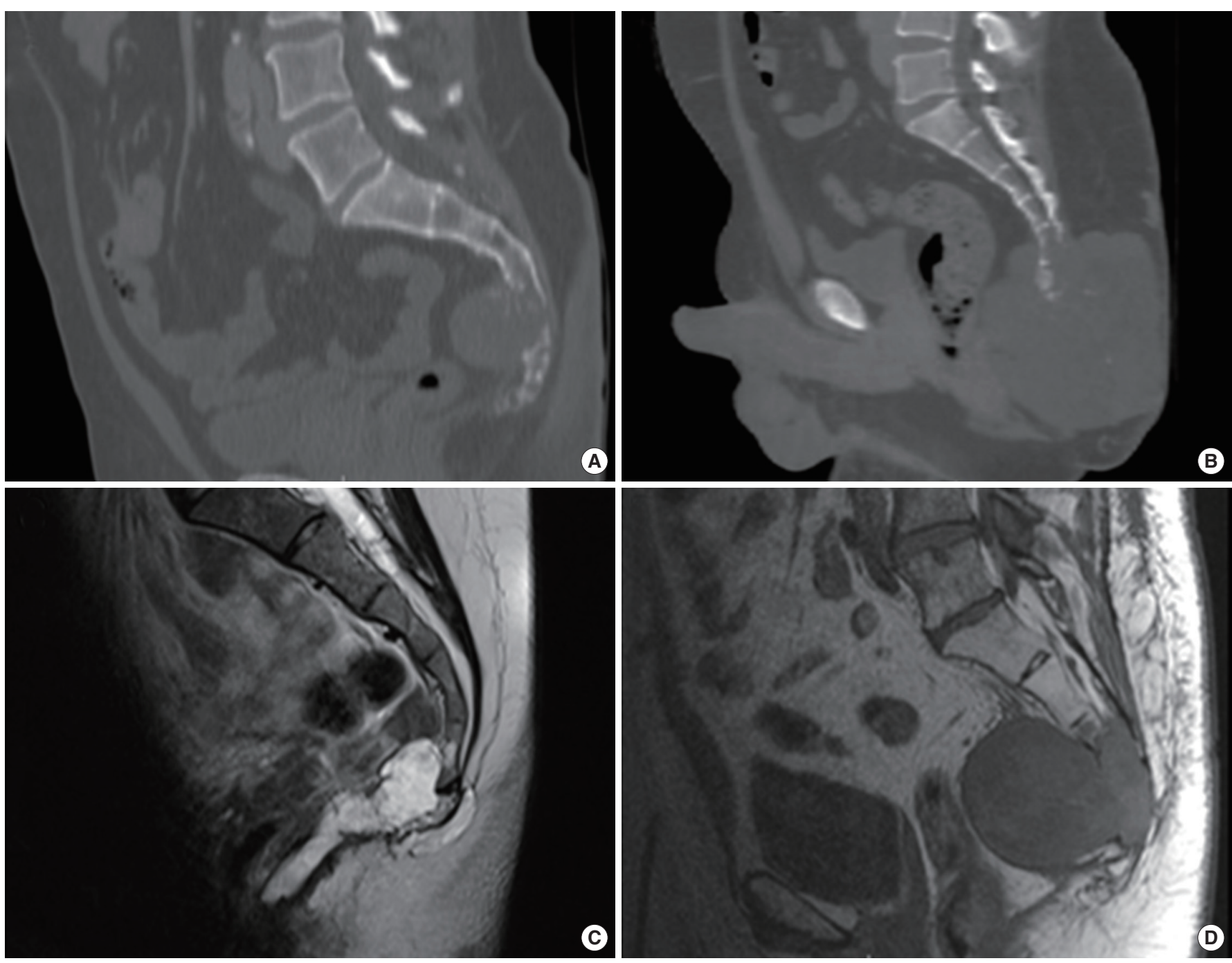

Fig. 2. (A) Pelvic computed tomography (CT) scan in the sagittal plane. Patient \#3 presented with a 5.5- $\mathrm{cm} \times 4-\mathrm{cm}$ chordoma at the S3-S4 level. (B) Pelvic CT scan in the sagittal plane. Patient \#7 presented with a $12.5-\mathrm{cm} \times 13-\mathrm{cm}$ mass infiltrating the mesorectum. (C) T-2 weighted pelvic magnetic resonance imaging (MRI) in the sagittal plane. Patient \#6 presented with a chordoma at the S3-S4 level and with distal progression. (D) T-1 weighted pelvic MRI in the sagittal plane. Patient \#5 presented with a chordoma at the S2 level and a pattern of infiltration towards deeper structures. 
The surgical strategy is best discussed at a multidisciplinary sarcoma tumor board in order to plan an R0 resection. For proximal chordomas and/or for chordomas infiltrating the mesorectum, a combined approach offers a better visualization of the proximal border of the tumor in the pelvis and allows removal of the anorectum en bloc with the sacral mass. For several authors, extension of the lesion above S3 is considered an obligation to perform a combined approach $[3,4,7]$. The risk of inadequate surgical margins is also related to the extension of the disease in the soft tissue. Hanna et al. [3] suggested that infiltration of the musculature adjacent to the sacrum and/or involvement of the sacroiliac joints increases the tendency for LR, even after an apparently-successful en bloc resection. All patients with invasion of surrounding muscle had a higher recurrence rate (76.9\%). Similarly, Chen et al. [13] showed that the presence of muscle invasion was a significant adverse factor for disease-free survival (DFS). Such a clinical presentation usually indicates an advanced stage and is frequently associated with progression, even when a R0 resection is performed, as for patient \#7 of our series. Smaller and distal lesions can be resected through a less invasive, posterior only approach [4, 24-27]. In our study, two patients (\#1 and \#2) with recurrence underwent a posterior approach only. These two patients radiologically had no sign of mesorectal infiltration and had an intact anorectum. However, in one patient, multiple pelvic implants that precluded an R0 resection were discovered intraoperatively. In the second patient, the distinction between the tumour and healthy tissues was difficult to assess because of previous surgery and radiotherapy.

Bladder and bowel dysfunction, motor deficits, lymphatic complications, pelvic hematomas, and cerebrospinal fluid fistulae are commonly reported in the literature as postoperative complications after resection of a sacral chordoma [7, 28-31]. As we observed, wound dehiscence after a sacrectomy remains the most significant postoperative complication (25\%-46\%) [30, 31]. Chen et al. [3] found that albumin $<3.0 \mathrm{~g} / \mathrm{dL}$, operating times $>6$ hours and previous surgery were statistically significant risk factors for wound infection after sacral tumor surgery.

Adjuvant treatment for a sacral chordoma remains controversial. Chordomas are known to be radio-resistant to a standard dose of RT ( $\leq 60$ Gray) $[32,33]$. Surrounding structures like the bladder, small bowel and sacral plexus are radiosensitive and impose limits to the extent of RT. Cheng et al. [14] described a possible beneficial effect of adjuvant RT on the DFS but not on the OS. Noel et al. [34] reported an 80.5\% 5-year survival for 100 patients with a skull-base chordoma who were treated with high-dose RT (>60 Gray). Modern RT techniques, like intensity modulated radiotherapy (IMRT), offer the possibility for an integrated boost concept with dose escalation while reducing the dose to organs at risk in proximity to the tumor due to a more conformal dose distribution. In the study of Zabel-du-Bois et al. [15], 34 patients with a sacral chordoma were treated with postoperative IMRT or with IMRT alone. Patients treated at the time of initial diagnosis showed a significant higher local control rate (47\%) compared with patients treated with IMRT for recurrent disease (24\%). Patients receiving $>60$ Gray had a significantly improved OS compared with patients treated with $\leq 60$ Gray $(85 \%$ vs $43 \%, \mathrm{P}<0.01)$. Moojen et al. [11] in a series of 15 patients showed a benefit with RT (>50 Gray) after LR in terms of local control and OS. In 10 patients with a R0 resection who developed a LR, 6 had RT with a mean survival of 7 years, suggesting a possible benefit of RT for recurrent disease after radical surgery.

No studies have assessed the role of neo-adjuvant RT for treating a sacral chordoma. We decided to use this approach in one patient (\#5) with extensive disease by analogy to a retroperitoneal sarcoma. Preoperative RT may provide less gastrointestinal toxicity and better delineation of the tumor, with the possibility to obtain a sterilized surgical field and a pseudo-capsule around the tumor $[35,36]$. Nevertheless, no decrease in tumor size was observed four weeks after the end of the neoadjuvant RT. Histopathology did not show any postradiation tumor necrosis or fibrosis.

No chemotherapy has proven any benefit in term of OS and local control in patients with a chordoma. The advent of moleculartargeted therapies has offered some encouraging alternatives for the management of advanced disease. Imatinib mesylate, associated with the cisplatine or the mechanistic target of rapamycin (mTOR) inhibitor, can be used in recurrent nonoperable or locally nontreatable chordomas and in metastatic disease [37, 38]. Stacchiotti et al. [39] described the use of imatinib mesylate in a phase II study of 56 patients with progressive disease. They demonstrated a clinical benefit in 35 patients, but reduction in tumor size was observed in 9 only. Tamborini et al. [40] suggested that the clinical benefit observed in chordoma patients treated with imatinib mesylate was related to switching off PDGFRB, PDGFRA and Kit. Based on these results, we treated two of our patients with imatinib mesylate. One patient is still alive with residual disease 14 years after the primary diagnosis, and one patient died of disease after 11 years. Further studies are necessary to confirm the role of molecular-targeted therapy in an adjuvant setting for sacral chordoma therapy.

Other treatment modalities for a sacral chordoma have been described in the literature. Cryosurgery for bone tumors was first described by Marcove et al. [41]. Other authors have used it as an adjuvant therapy for sacral tumors including chordomas [42]. We performed cryosurgery in one patient with poor performance status for a sacral tumour of $4 \mathrm{~cm} \times 3 \mathrm{~cm}$. He is currently alive with residual disease two years after treatment. This could be an effective alternative for patients with a single well-defined lesion who are unfit for surgery.

Perineal reconstruction after radical extended resection for a sacral chordoma may become very complex and require the involvement of plastic surgeons. The key point of reconstruction is to provide stable and vascularized soft-tissue coverage to fill dead spaces and a solid pelvic floor and to avoid deep infections in body areas particularly at risk of bacterial contamination [43]. The type of reconstruction depends on the size of the pelvic de- 
fect. Small sacral defects may be treated like pressure sores and reconstructed by using muscular or fasciocutaneous gluteal flaps [43]. These are vascularized by superior or inferior gluteal arteries and can be designed as rotational flaps or advancement flaps in a $\mathrm{V}-\mathrm{Y}$ shape $[44,45]$. We used rotational fasciocutaneous gluteal flaps in two of our patients, for primary reconstruction in one and for complementary reconstruction in the other. When the residual empty space in the pelvis is too large, it must be filled with healthy tissue. In addition, the gluteal arteries vascularizing the gluteal flaps may have been sacrificed during oncologic resection. The transpelvic vertical rectus abdomini myocutaneous flap has been described for vaginal and pelvic reconstruction $[43,46]$. It is usually avoided in patients who have undergone a laparotomy because of significant donor site morbidity, like fascial dehiscence, a hernia and an imbalance of truncal core muscular support [47, 48]. Moreover, the muscle and skin paddle may be insufficient. Free flaps can be another choice, but access to recipient vessels at the wound site may be challenging [43]. Two of our patients presented huge defects requiring not only a large skin paddle but also a considerable amount of muscular tissue to fill the pelvic defect and to reconstruct the perineum. For these reasons, we used ALT flaps associated with the vastus lateralis muscle to create a composite myocutaneous flap [43, 49]. This type of flap has a long vascular pedicle and a large skin paddle and can be raised with the muscolocutaneous perforators that feed the muscle part. Thanks to the long pedicle and to the big arc of rotation, the flap can be transferred to cover the posterior defect. Complication rates in perineal and sacral reconstructions of very large defects can exceed $50 \%$, especially in association with high-dose RT, obesity and diabetes [43], as encountered in our patient \#5. Liver failure (patient \#7) can increase operative risk by affecting tissue quality and wound healing [50].

Our study has several limitations. The number of patients included was small because of the rarity of this disease, but these patients shared a common complex pelvic presentation. Furthermore, follow-up was short for the last three patients, who recently underwent surgery. We were unable to apply the Enneking classification [51] for musculoskeletal neoplasms, which is used by others to report the resection status of a sacral chordoma, as the pathologist seldom described a reactive tissue around the tumor pseudo-capsule, which represents the demarcation between a marginal and a wide resection margin. However, the R classification is a strong indicator of prognosis and facilitates comparison of treatment results if applied in a constant manner [52].

In conclusion, despite the obvious limitations of our study, our results highlight the difficulty of obtaining clear margins with redone surgery because of initially-misdiagnosed chordomas. A primary R0 resection still remains the gold standard for the treatment of this tumor, but is no guarantee of a cure, especially in patients with tumors extending into the musculature. Even in correctly-diagnosed patients treated in a tertiary center, a definitive cure of the disease remains difficult to obtain despite a multidisci- plinary approach with modern adjuvant therapies. Reconstructive surgery may be challenging in these situations, and an ALT flap could be a good option in selected patients. Due to the rarity of the disease, randomized studies are unlikely to be performed, and creation of national prospective databases could help improve the prognosis for such patients.

\section{CONFLICT OF INTEREST}

No potential conflict of interest relevant to this article was reported.

\section{REFERENCES}

1. Jemal A, Siegel R, Ward E, Murray T, Xu J, Thun MJ. Cancer statistics, 2007. CA Cancer J Clin 2007;57:43-66.

2. Chugh R, Tawbi H, Lucas DR, Biermann JS, Schuetze SM, Baker LH. Chordoma: the nonsarcoma primary bone tumor. Oncologist 2007;12:1344-50.

3. Hanna SA, Aston WJ, Briggs TW, Cannon SR, Saifuddin A. Sacral chordoma: can local recurrence after sacrectomy be predicted? Clin Orthop Relat Res 2008;466:2217-23.

4. Ruggieri P, Angelini A, Ussia G, Montalti M, Mercuri M. Surgical margins and local control in resection of sacral chordomas. Clin Orthop Relat Res 2010;468:2939-47.

5. Baratti D, Gronchi A, Pennacchioli E, Lozza L, Colecchia M, Fiore M, et al. Chordoma: natural history and results in 28 patients treated at a single institution. Ann Surg Oncol 2003;10:291-6.

6. Jawad MU, Scully SP. Surgery significantly improves survival in patients with chordoma. Spine (Phila Pa 1976) 2010;35:117-23.

7. Fuchs B, Dickey ID, Yaszemski MJ, Inwards CY, Sim FH. Operative management of sacral chordoma. J Bone Joint Surg Am 2005; 87:2211-6.

8. Hulen CA, Temple HT, Fox WP, Sama AA, Green BA, Eismont FJ. Oncologic and functional outcome following sacrectomy for sacral chordoma. J Bone Joint Surg Am 2006;88:1532-9.

9. Higinbotham NL, Phillips RF, Farr HW, Hustu HO. Chordoma. Thirty-five-year study at Memorial Hospital. Cancer 1967;20:184150 .

10. Chambers PW, Schwinn CP. Chordoma: a clinicopathologic study of metastasis. Am J Clin Pathol 1979;72:765-76.

11. Moojen WA, Vleggeert-Lankamp CL, Krol AD, Dijkstra SP. Longterm results: adjuvant radiotherapy in en bloc resection of sacrococcygeal chordoma is advisable. Spine (Phila Pa 1976) 2011;36: E656-61.

12. Ferraresi V, Nuzzo C, Zoccali C, Marandino F, Vidiri A, Salducca N, et al. Chordoma: clinical characteristics, management and prognosis of a case series of 25 patients. BMC Cancer 2010;10:22.

13. Chen KW, Yang HL, Lu J, Liu JY, Chen XQ. Prognostic factors of sacral chordoma after surgical therapy: a study of 36 patients. Spinal Cord 2010;48:166-71.

14. Cheng EY, Ozerdemoglu RA, Transfeldt EE, Thompson RC Jr. 
Lumbosacral chordoma. Prognostic factors and treatment. Spine (Phila Pa 1976) 1999;24:1639-45.

15. Zabel-du Bois A, Nikoghosyan A, Schwahofer A, Huber P, Schlegel W, Debus J, et al. Intensity modulated radiotherapy in the management of sacral chordoma in primary versus recurrent disease. Radiother Oncol 2010;97:408-12.

16. Fleming ID, Cooper JS, Jenson DE, Hutter RV, Kennedy BJ, Murphy GP, et al. American Joint Committee on Cancer manual for staging of cancer. 5th ed. Philadelphia: J.B. Lippincott; 1997.

17. Bergh P, Kindblom LG, Gunterberg B, Remotti F, Ryd W, MeisKindblom JM. Prognostic factors in chordoma of the sacrum and mobile spine: a study of 39 patients. Cancer 2000;88:2122-34.

18. Boriani S, Bandiera S, Biagini R, Bacchini P, Boriani L, Cappuccio $\mathrm{M}$, et al. Chordoma of the mobile spine: fifty years of experience. Spine (Phila Pa 1976) 2006;31:493-503.

19. Osaka S, Kodoh O, Sugita H, Osaka E, Yoshida Y, Ryu J. Clinical significance of a wide excision policy for sacrococcygeal chordoma. J Cancer Res Clin Oncol 2006;132:213-8.

20. Dahan H, Arrive L, Wendum D, Docou le Pointe H, Djouhri H, Tubiana JM. Retrorectal developmental cysts in adults: clinical and radiologic-histopathologic review, differential diagnosis, and treatment. Radiographics 2001;21:575-84.

21. Williams LS, Rojiani AM, Quisling RG, Mickle JP. Retrorectal cyst-hamartomas and sacral dysplasia: MR appearance. AJNR Am J Neuroradiol 1998;19:1043-5.

22. Lim KE, Hsu WC, Wang CR. Tailgut cyst with malignancy: MR imaging findings. AJR Am J Roentgenol 1998;170:1488-90.

23. Llauger J, Palmer J, Amores S, Bague S, Camins A. Primary tumors of the sacrum: diagnostic imaging. AJR Am J Roentgenol 2000;174:417-24.

24. Atalar H, Selek H, Yildiz Y, Saglik Y. Management of sacrococcygeal chordomas. Int Orthop 2006;30:514-8.

25. Devin C, Chong PY, Holt GE, Feurer I, Gonzalez A, Merchant N, et al. Level-adjusted perioperative risk of sacral amputations. J Surg Oncol 2006;94:203-11.

26. Samson IR, Springfield DS, Suit HD, Mankin HJ. Operative treatment of sacrococcygeal chordoma: a review of twenty-one cases. J Bone Joint Surg Am 1993;75:1476-84.

27. Stener B, Gunterberg B. High amputation of the sacrum for extirpation of tumors. Principles and technique. Spine (Phila Pa 1976) 1978;3:351-66. Erratum in: Rev Chir Orthop 1987;73:following 217.

28. Hsieh PC, Xu R, Sciubba DM, McGirt MJ, Nelson C, Witham TF, et al. Long-term clinical outcomes following en bloc resections for sacral chordomas and chondrosarcomas: a series of twenty consecutive patients. Spine (Phila Pa 1976) 2009;34:2233-9.

29. Guo Y, Palmer JL, Shen L, Kaur G, Willey J, Zhang T, et al. Bowel and bladder continence, wound healing, and functional outcomes in patients who underwent sacrectomy. J Neurosurg Spine 2005;3: 106-10.

30. Sciubba DM, Nelson C, Gok B, McGirt MJ, McLoughlin GS, Noggle JC, et al. Evaluation of factors associated with postopera- tive infection following sacral tumor resection. J Neurosurg Spine 2008;9:593-9.

31. Chen KW, Yang HL, Lu J, Wang GL, Ji YM, Bao ZH, et al. Risk factors for postoperative wound infections of sacral chordoma after surgical excision. J Spinal Disord Tech 2011;24:230-4.

32. Catton C, O'Sullivan B, Bell R, Laperriere N, Cummings B, Fornasier V, et al. Chordoma: long-term follow-up after radical photon irradiation. Radiother Oncol 1996;41:67-72.

33. Cummings BJ, Hodson DI, Bush RS. Chordoma: the results of megavoltage radiation therapy. Int J Radiat Oncol Biol Phys 1983; 9:633-42.

34. Noel G, Feuvret L, Calugaru V, Dhermain F, Mammar H, HaieMeder C, et al. Chordomas of the base of the skull and upper cervical spine. One hundred patients irradiated by a 3D conformal technique combining photon and proton beams. Acta Oncol 2005; 44:700-8.

35. Van De Voorde L, Delrue L, van Eijkeren M, De Meerleer G. Radiotherapy and surgery-an indispensable duo in the treatment of retroperitoneal sarcoma. Cancer 2011;117:4355-64.

36. Al-Absi E, Farrokhyar F, Sharma R, Whelan K, Corbett T, Patel M, et al. A systematic review and meta-analysis of oncologic outcomes of pre-versus postoperative radiation in localized resectable soft-tissue sarcoma. Ann Surg Oncol 2010;17:1367-74.

37. Casali PG, Stacchiotti S, Grosso F, Messina A, Crippa F, Tamborini E, et al. Adding cisplatin (CDDP) to imatinib (IM) re-estabishes tumor response following secondary resistance to IM in advanced chordoma [abstract]. J Clin Oncol 2007;25(18S). Abstract no. 10038.

38. Mancini M, Corradi V, Petta S, Martinelli G, Barbieri E, Santucci MA. mTOR inhibitor RAD001 (Everolimus) enhances the effects of imatinib in chronic myeloid leukemia by raising the nuclear expression of c-ABL protein. Leuk Res 2010;34:641-8.

39. Stacchiotti S, Longhi A, Ferraresi V, Grignani G, Comandone A, Stupp R, et al. Phase II study of imatinib in advanced chordoma. J Clin Oncol 2012;30:914-20.

40. Tamborini E, Miselli F, Negri T, Lagonigro MS, Staurengo S, Dagrada GP, et al. Molecular and biochemical analyses of platelet-derived growth factor receptor (PDGFR) B, PDGFRA, and KIT receptors in chordomas. Clin Cancer Res 2006;12:6920-8.

41. Marcove RC, Miller TR, Cahan WC. The treatment of primary and metastaticbone tumors by repetitive freezing. Bull N Y Acad Med 1968;44:532-44.

42. Kollender Y, Meller I, Bickels J, Flusser G, Issakov J, Merimsky O, et al. Role of adjuvant cryosurgery in intralesional treatment of sacral tumors. Cancer 2003;97:2830-8.

43. Miles WK, Chang DW, Kroll SS, Miller MJ, Langstein HN, Reece GP, et al. Reconstruction of large sacral defects following total sacrectomy. Plast Reconstr Surg 2000;105:2387-94.

44. Chen TH. Bilateral gluteus maximus V-Y advancement musculocutaneous flaps for the coverage of large sacral pressure sores: revisit and refinement. Ann Plast Surg 1995;35:492-7.

45. Erba P, di Summa PG, Raffoul W, Schaefer DJ, Kalbermatten DF. 
Tip anchor flap in decubital surgery. Aesthetic Plast Surg 2011; 35:1133-6.

46. Tobin GR, Day TG. Vaginal and pelvic reconstruction with distally based rectus abdominis myocutaneous flaps. Plast Reconstr Surg 1988;81:62-73.

47. Baumann DP, Butler CE. Component separation improves outcomes in VRAM flap donor sites with excessive fascial tension. Plast Reconstr Surg 2010;126:1573-80.

48. Buchel EW, Finical S, Johnson C. Pelvic reconstruction using vertical rectus abdominis musculocutaneous flaps. Ann Plast Surg 2004;52:22-6.

49. Ng RW, Chan JY, Mok V, Li GK. Clinical use of a pedicled anterolateral thigh flap. J Plast Reconstr Aesthet Surg 2008;61:158-64.

50. Chen SY, Fu JP, Chen TM, Chen SG. Reconstruction of scrotal and perineal defects in Fournier's gangrene. J Plast Reconstr Aesthet Surg 2011;64:528-34.

51. Staging of musculoskeletal neoplasms. Musculoskeletal Tumor Society. Skeletal Radiol 1985;13:183-94.

52. Wittekind C, Compton CC, Greene FL, Sobin LH. TNM residual tumor classification revisited. Cancer 2002;94:2511-6.

53. Ahmed AR. Safety margins in resection of sacral chordoma: analysis of 18 patients. Arch Orthop Trauma Surg 2009;129:483-7.

54. Schwab JH, Healey JH, Rose P, Casas-Ganem J, Boland PJ. The surgical management of sacral chordomas. Spine (Phila Pa 1976) 2009;34:2700-4.

55. Asavamongkolkul A, Waikakul S. Wide resection of sacral chordoma via a posterior approach. Int Orthop 2012;36:607-12. 